\title{
Rice-Based Products for Consumers in Sierra Leone
}

\author{
Kemoh Bangura, Rugiatu Conteh, Mohamed Sow and Nazir Mahmood
}

Rokupr Agricultural Research Center (RARC)/Sierra Leone Agricultural Research Institute (SLARI), Tower Hill, Freetown

\begin{abstract}
Different rice-based products were promoted among rural women and youths through demonstrations, participatory evaluation and training in their use for income generation. The utilization of the rice-based products has contributed to enhanced food self sufficiency and increased the income for women and youths.
\end{abstract}

\section{Introduction}

Rice is the staple food and therefore the most important crop in Sierra Leone. It constitutes most parts of our diets and provides a substantial amount of dietary energy. In Sierra Leone, rice is usually eaten with sauce prepared from fish, meat, vegetables, and legumes such as beans. The objective of this study was to develop and promote rice-based products among women and youths and their use for income generation.

\section{Nutritive value of rice}

\begin{tabular}{|l|l|}
\hline Protein & $7-16 \%$ \\
\hline Fat & $0.4-1 \%$ \\
\hline Carbohydrate & $75-90 \%$ \\
\hline
\end{tabular}

\section{Materials and Methods}

150 women and youths marketers were trained on the preparation of different rice-based products.

\section{Making rice flour}

Rice flour was prepared using the dry or wet method

\section{The dry method}

- The impurities of the rice whole grain are physically removed, grinded using a machine and sieved with a $0.02 \mathrm{~mm}$ sieve to obtain the rice flour used in making confectioneries, cakes and different products

\section{The wet method}

- The whole grain rice was soaked in water for about 15-20 minutes.

- After soaking, rice was gargled several times using a calabash until all the sand is removed.

- The rice was rinsed and then water was drained completely.

- Using a mortar and a pestle, rice was pounded and sieved with a $0.02 \mathrm{~mm}$ to obtained the flour.

- The flour was then dried in the sunlight.
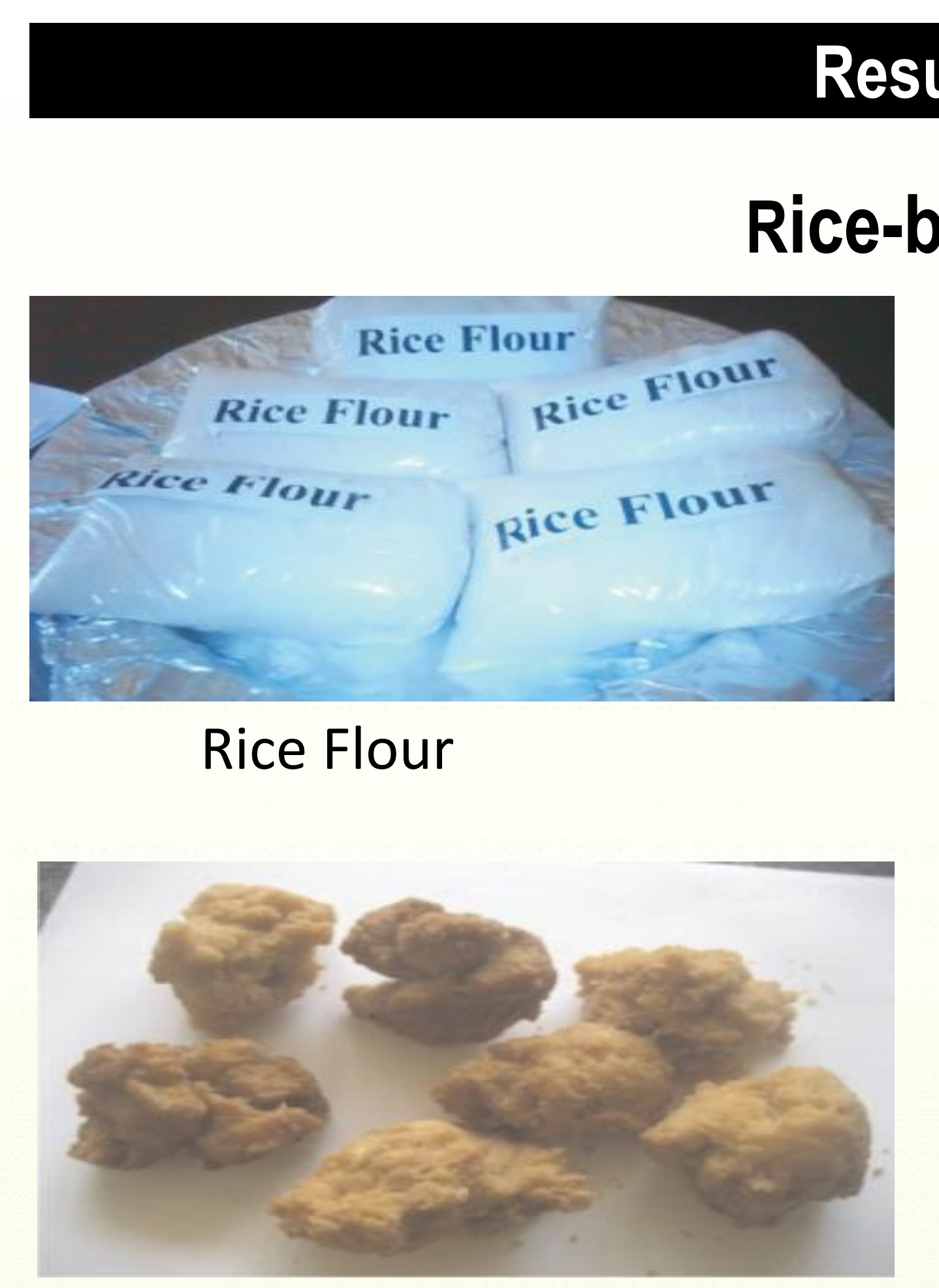

Rice/Wheat Flour Doughnut

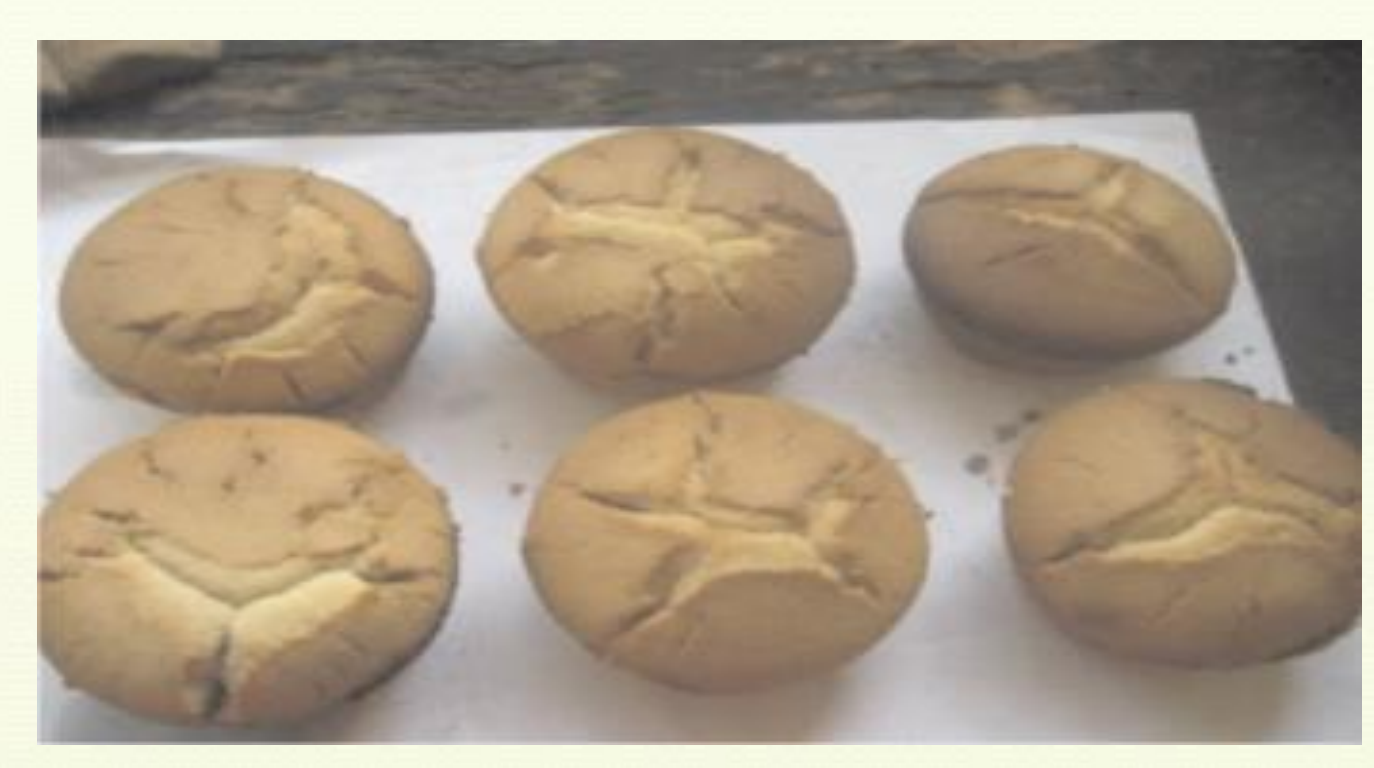

Rice/Wheat Flour Rich Cake

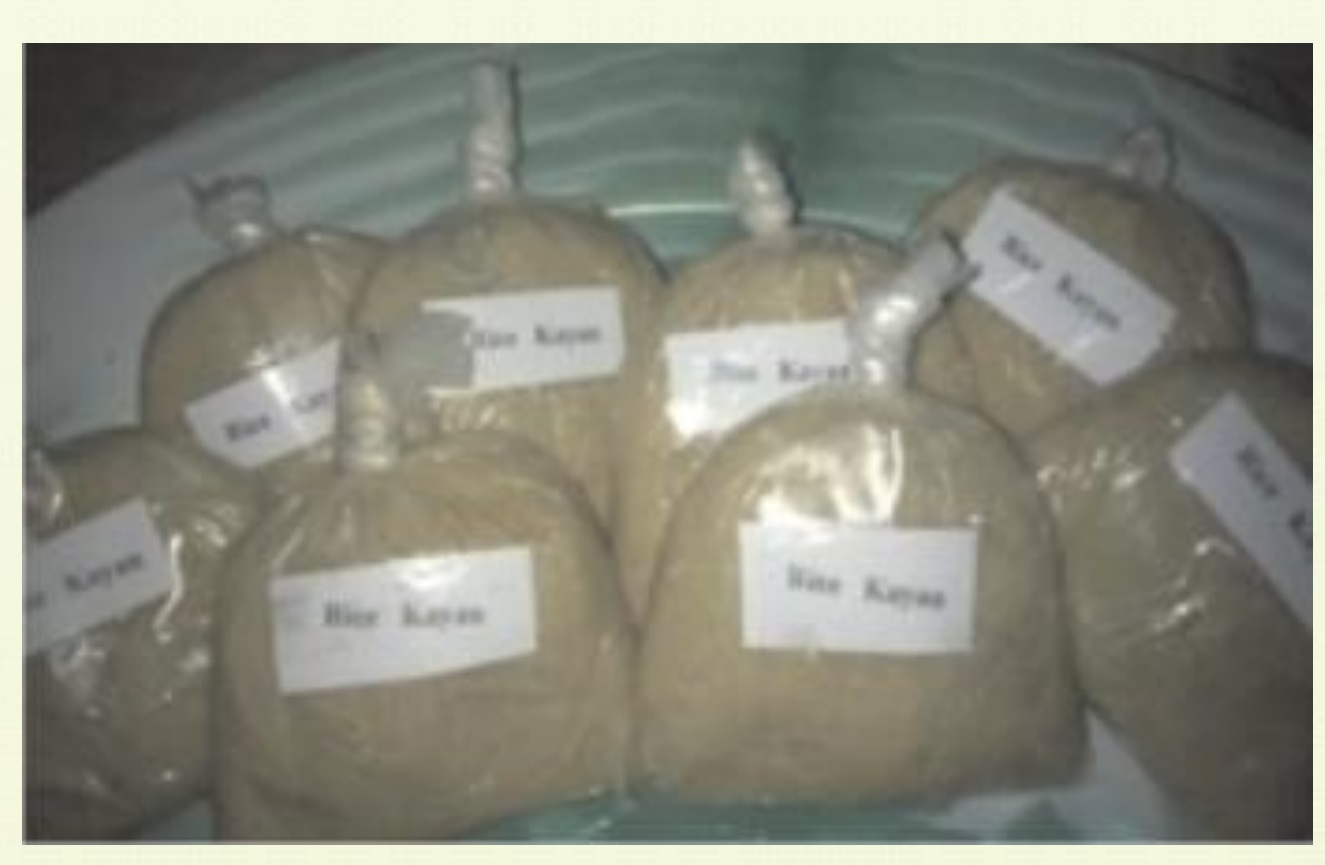

Rice Kayan
Rice Flour
Results

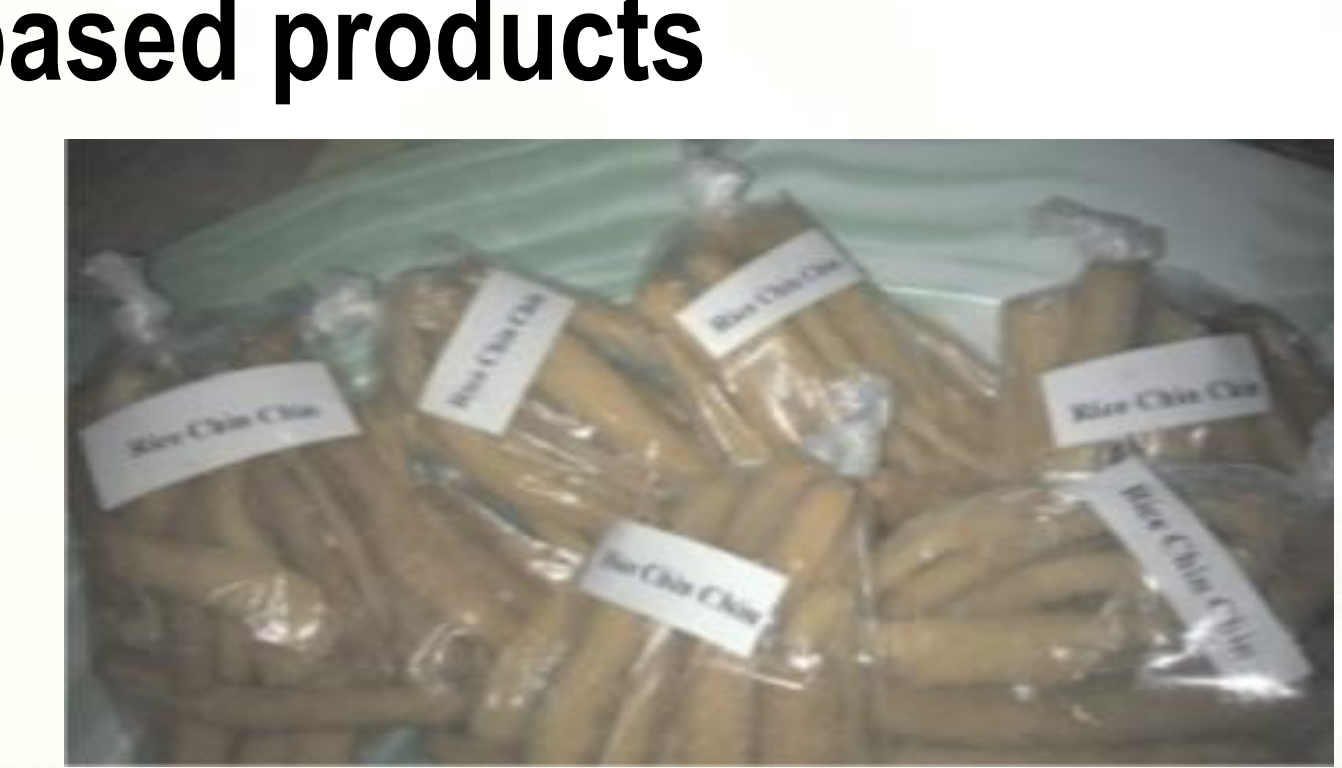

Rice/Wheat Flour Chin Chin

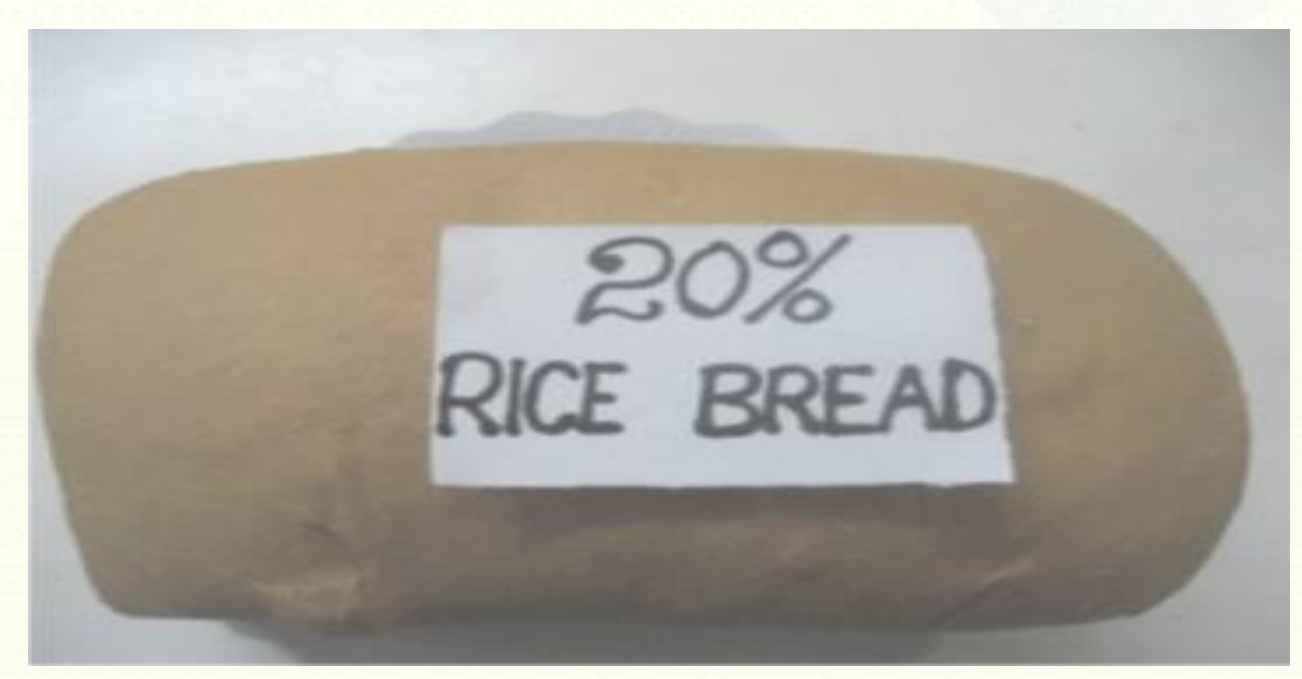

$80 \%$ Wheat Flour and 20\% Rice Flour Bread

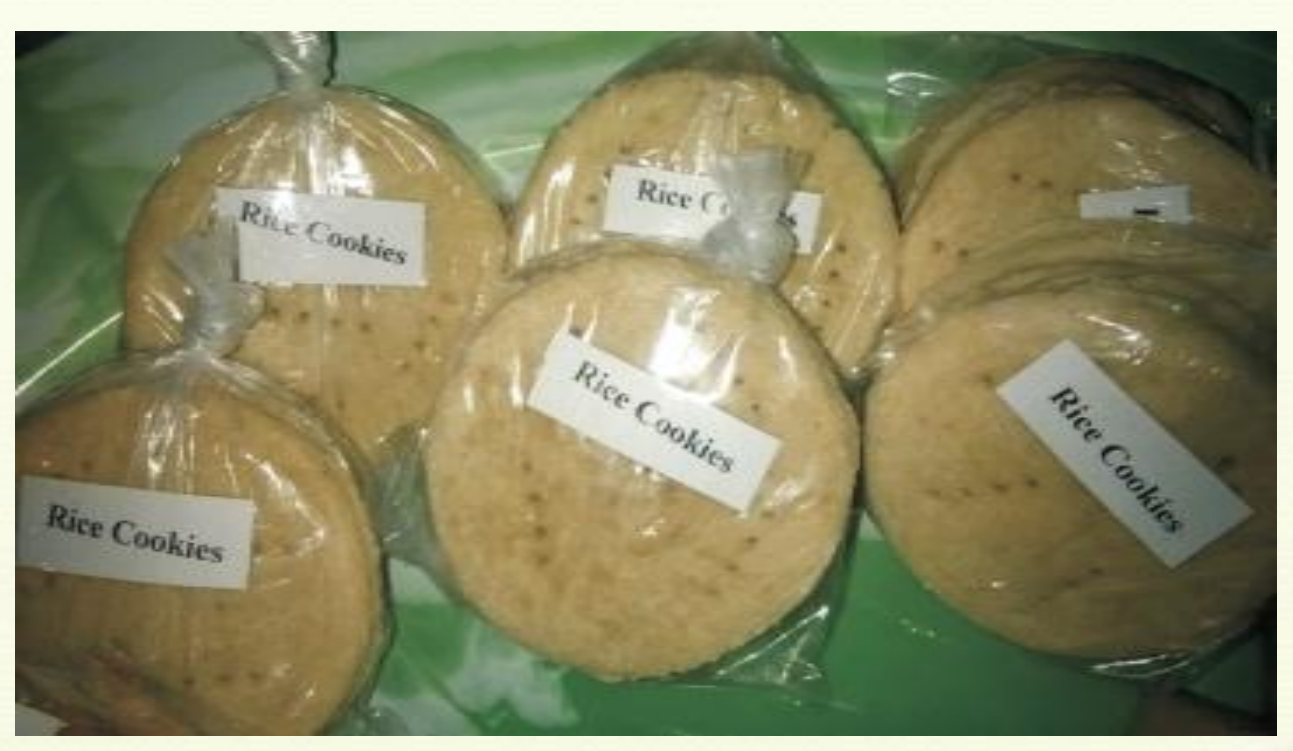

Rice/Wheat Flour Cookies

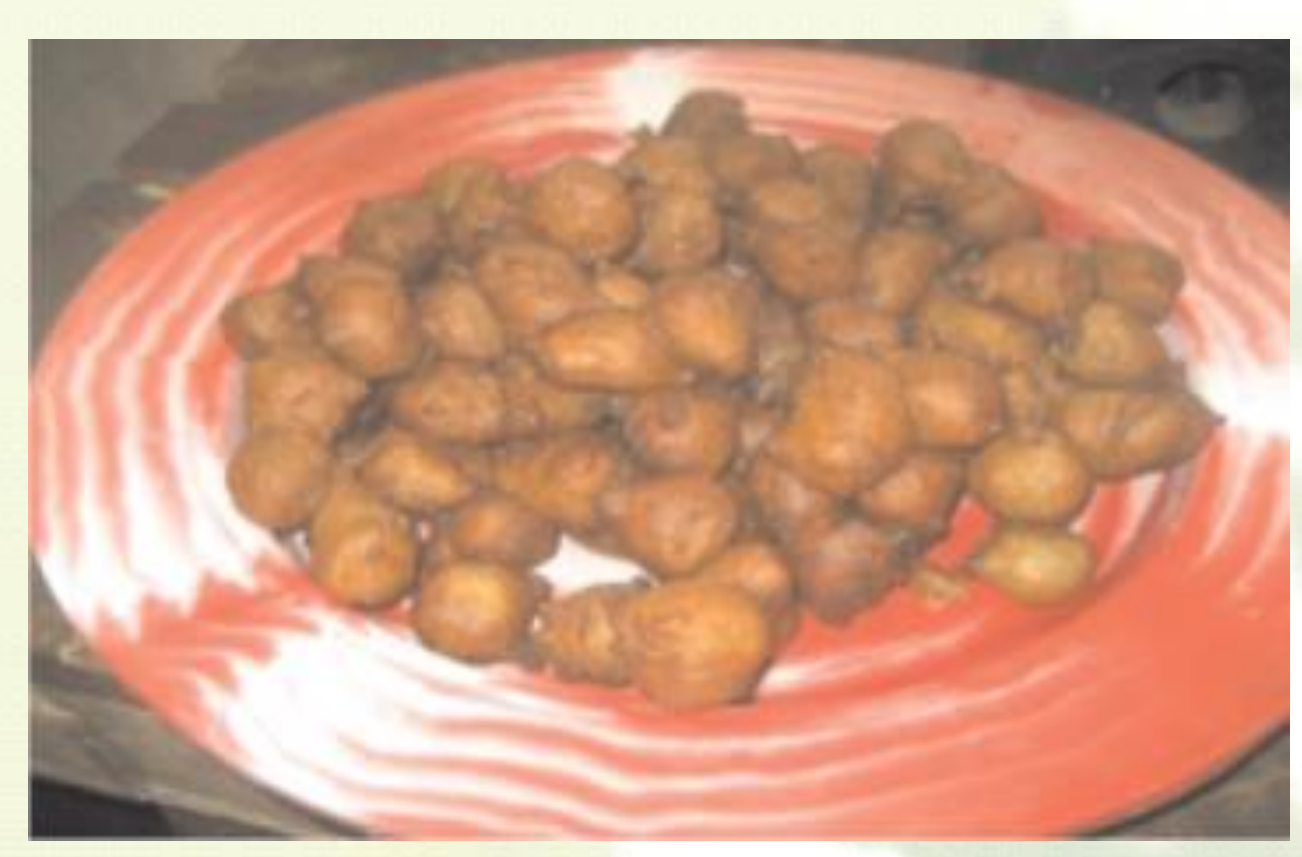

Rice/Wheat Flour Akara

\section{Conclusions}

Rice can be utilized in several ways in Sierra Leone, including the preparation of Rice/Wheat Flour Akara; Rice/Wheat Flour Doughnut; Rice/Wheat Flour Rich Cake, Rice/Wheat/Flour Cookies; Kayan; Rice/Wheat Flour Bread; and so on. These rice-based products were promoted among rural women through demonstrations, participatory evaluation and training in their use for income generation. The utilization of these rice-based products with higher nutritional value has contributed to reduce the burden of malnutrition in Sierra Leone, hence food self sufficiency will also be enhanced.

\section{Acknowledgements}

The study was funded by AfricaRice with funds provided by the government of Canada under the GAC project.

Drs Ali Toure (Agricultural Economist) and Olupomi Ajayi (Rice Research Coordinator), AfricaRice, for contributing greatly to the implementation of this study. 